\title{
Mapping and Spatial Pattern Analysis of COVID -19 in Central Iran Using the Local Indicators of Spatial Association (LISA)
}

Nahid Jesri

Shahid Beheshti University

Abedin Saghafipour ( $\nabla$ abed.saghafi@yahoo.com )

Qom University of Medical Sciences and Health Services https://orcid.org/0000-0003-3595-6347

Alireza Koopaei

Qom University of Medical Sciences and Health Services

Babak Farzinnia

Qom University of Medical Sciences and Health Services

Moharram Karami Jooshin

Qom University of Medical Sciences and Health Services

Samaneh Abolkheirian

Tehran University of Medical Sciences

Mahsa Sarvi

Qom University of Medical Sciences and Health Services

\section{Research}

Keywords: Coronavirus, COVID -19, Spatial analysis, Iran

Posted Date: July 22nd, 2021

DOl: https://doi.org/10.21203/rs.3.rs-732635/v1

License: (c) (i) This work is licensed under a Creative Commons Attribution 4.0 International License.

Read Full License

Version of Record: A version of this preprint was published at BMC Public Health on December 1st, 2021. See the published version at https://doi.org/10.1186/s12889-021-12267-6. 


\title{
Mapping and Spatial Pattern Analysis of COVID -19 in Central Iran Using the local indicators of spatial association (LISA)
}

\author{
Nahid Jesri ${ }^{1}$, Abedin Saghafipour ${ }^{2 *}$, Alireza Koopaei ${ }^{3}$, Babak Farzinnia ${ }^{4}$, Moharram Karami \\ Jooshin $^{5}$, Samaneh Abolkheirian ${ }^{6}$, Mahsa Sarvi ${ }^{7}$ \\ ${ }^{1}$ Remote Sensing \& GIS Centre, Shahid Beheshti University, Tehran, Iran \\ ${ }^{2}$ Department of Public Health, Faculty of Health, Qom University of Medical Sciences, Qom, Iran \\ ${ }^{3}$ Occupational health \& Safety Department, Faculty of Health, Qom University of Medical Sciences, Qom, Iran. \\ ${ }^{4}$ Department of Environmental Health Engineering, Faculty of Health, Qom University of Medical Sciences, Qom, \\ Iran \\ ${ }^{5}$ Department of Disease Control and Prevention, Qom Provincial Health Center, Qom University of Medical \\ Sciences, Qom, Iran \\ ${ }^{6}$ Department of Health Education and Promotion, School of Public Health, Tehran University of Medical Sciences, \\ Tehran, Iran \\ ${ }^{7}$ Student Research Committee, Qom University of Medical Sciences, Qom, Iran
}

Corresponding Author: Abedin Saghafipour, Postal Address: Department of Public Health, Faculty of Health, Qom University of Medical Sciences, Qom, Iran.

E-mail: abed.saghafi@yahoo.com

\begin{abstract}
Background: Using geographical analysis to identify geographical factors affecting the prevalence of COVID-19 infection can effect on public health policies to control of the virus. The aim of this study was to determine the spatial analysis of COVID-19 regions in Qom Province, using the local indicators of spatial association (LISA).

In a descriptive-analytical study, the total number of individuals infected with COVID-19 in Qom Province, from February 19, to September 2020, were included in the study. The spatial distribution in urban areas was determined using the Moran coefficient in GIS. in addition, the spatial autocorrelation of the coronavirus in the different urban districts of the province was calculated using LISA method.

Results: The prevalence of COVID -19 in Qom province was estimated to be 356.75 per 100,000 populations. The pattern of spatial distribution of the prevalence of COVID -19 in Qom was clustered. The District 3 (Imam Khomeini St.), and District 6 (Imamzadeh Ebrahim St.), were set in HH category of LISA as two foci of COVID-19 in Qom province.

Conclusions: Based on LISA, District 1 (Bajak) of urban districts was set in LH category. It means this district is located in a low value area surrounded by high values. One of the most important geographical factors affecting the incidence of coronavirus is based on spatial distribution model, distance and spatial proximity. So, health policy makers, should impose more restrictions on the observance of health protocols to control of the coronavirus.
\end{abstract}

Keywords: Coronavirus; COVID -19; Spatial analysis; Iran

\section{Bachground}


In late 2019, a novel virus called severe acute respiratory syndrome coronavirus 2 (SARS-CoV-2) was identified in Wuhan, Hubei Province, China, which was reported to be the cause of cases of pneumonia. The disease spread rapidly and after the epidemic in China, its cases increased throughout the world [1]. In February 2020, the World Health Organization (WHO) has announced that the disease caused by the novel virus would be called COVID-19 [2]. The United Nations has described the coronavirus as a major social, humanitarian and economic crisis that which will leave many adverse effects on different countries [3]. The COVID-19 is mainly transmitted through respiratory droplets that are spread by coughing, or sneezing or exhaling through the mouth and nose of a person with the disease. The infection also spreads to the infectious droplets around the patient and its surfaces. Then other people become infected with COVID-19 by touching the contaminated equipment or surfaces when those droplets get into their eyes, mouth or nose [4]. This disease has indirect and potential impacts on the public health in all groups of people [5]. Despite significant advances in disease control, communicable diseases are still of particular importance in epidemiology and community health [6].

One of the main applications of epidemiology is to facilitate the identification of geographical data affected by disease and vulnerable groups that are at higher risk of disease and exposure to risk factors for mortality. Identification of those geographical areas and at risk groups help to use appropriate health measures to reduce risk factors of the infectious disease [7]. The first step in analyzing geographic data is to visualize it, especially in the form of geographic maps, which clearly show the pattern of geographical distribution of diseases, injuries, and deaths and pave the way for the creation of causal hypotheses [8]. In recent years, the use of GIS in order to determining of geographical distribution patterns of diseases in medical and health sciences has increased significantly [9-11]. Determining the geographical distribution of diseases, spatial study of care facilities and health services, determining the geographical boundaries of communities that are essential components of epidemiological and health studies are some of the applications of GIS in the field of health [12]. Spatial modeling in GIS is directly used to understand the differences in the spatial distribution of diseases and their relationship with environmental factors and health care system, so that GIS technology is currently a major tool in health research in the field of infectious diseases [13]. 
In order to determine spatial patterns of disease, the local indicators of spatial association (LISA) in the environmental GIS is very helpful. This model is a set of methods to describe and visualize spatial distributions; identify atypical locations or spatial outliers; determine patterns of spatial association, clusters or hot-spots; and propose spatial regimes or other shapes of spatial heterogeneity [14]. Due to the prevalence of COVID -19 pandemic in the world as well as in Iran and Qom province and the need to control and prevent the distribution of this disease as much as possible, it is necessary to determine the spatial pattern and geographical distribution of the disease in different districts and areas of Qom Province and identify its high-risk areas. So that control and preventive measures can be carried out more purposefully. Therefore, this study was designed to determine the spatial distribution pattern analysis of COVID-19 in central Iran using the LISA method.

\section{Methods}

Qom Province is one of the central provinces of Iran with an area of about 11,526 $\mathrm{km}^{2}$, located in the south of Tehran Province, north of Isfahan Province, east of Markazi Province and west of Semnan Province, which is located in an arid and semi-arid region and therefore it has a desert and semi-desert climate with the average annual temperature has been recorded as $18.17{ }^{\circ} \mathrm{C}$ [15]. According to the latest census of the Statistics Center of Iran, the population of this province is 129,223 people. Geographically, this province includes 5 rural districts: Markazi, Salafchegan, Kahak, Khalajistan and Jafarabad (Figure 1). The city of Qom, as a subset of the Markazi district, is the only urban area of the province and has 8 urban districts. These districts include: District 1 (Bajak), District 2 (Niroogah), District 3 (Imam Khomeini street), District 4 (Janbilabad-Salarieh), District 5 (Jamkaran), District 6 (Imamzadeh Ebrahim Street), District 7 (Holy shrine) and District 8 (Pardisan). Following the COVID-19 infection pandemic in the world, the outbreak of this disease in Iran and from the city of Qom on February 20, 2020 was confirmed and announced [16]. 


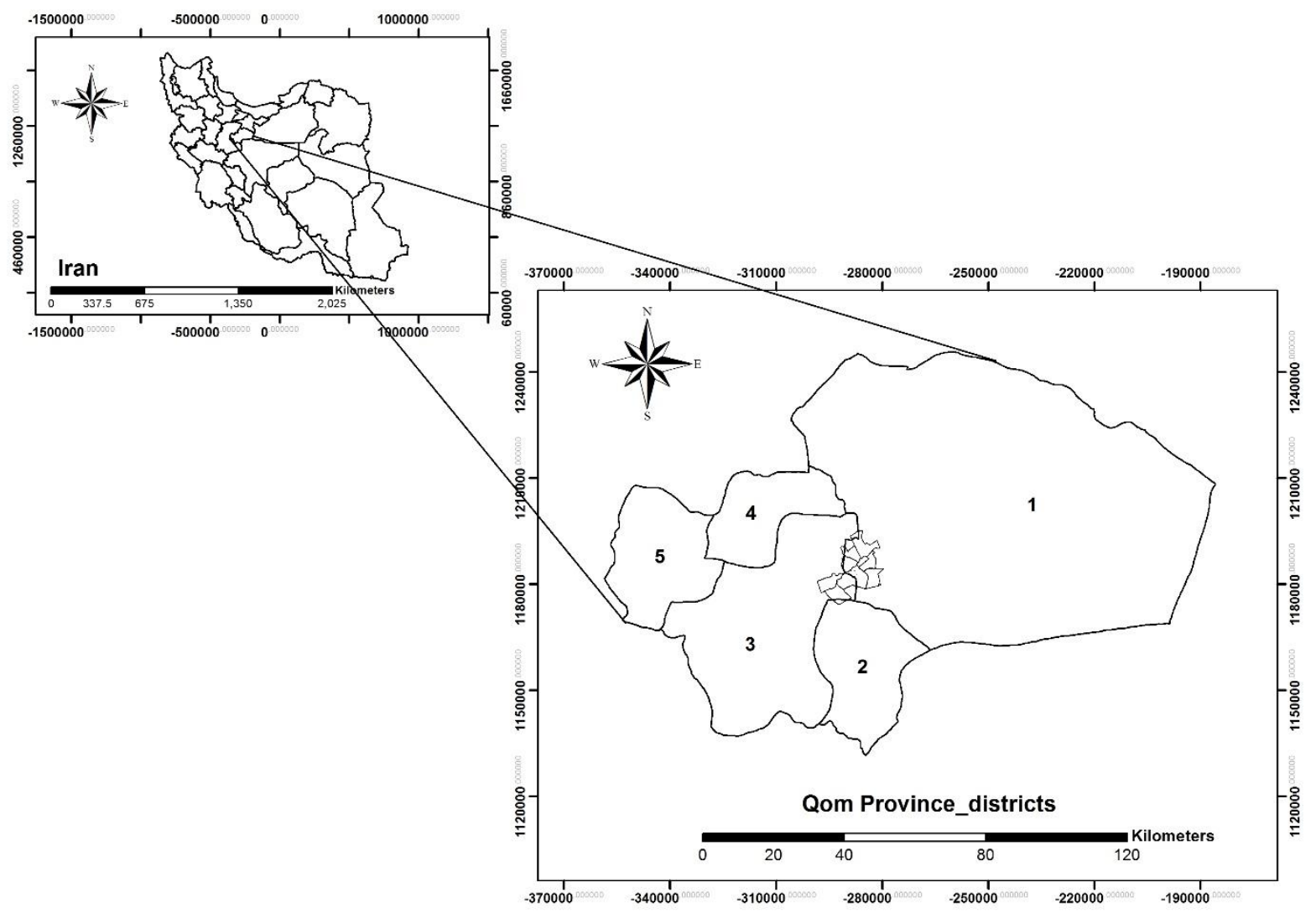

Fig. 1 The study area; Qom province in central Iran, rural districts (1: Markazi, 2: Kahak, 3: Salafchegan, 4: Jafarabad and 5: Khalajestan) and urban district (Qom City)

In a descriptive-analytical study, the total number of individuals infected with COVID-19 $(\mathrm{n}=4388)$ in Qom Province, central Iran from February 19, 2020 to September, were included in the study. The data of patients was recorded through the emergency medical records of the hospitals under supervision of Qom University of Medical Sciences. The population of area was prepared separately according on the postal address of patients in Qom Province and finally the analysis was performed in Arc GIS software. After data collection in Microsoft Office Excel 2010, and entering the data in ArcGIS 10.6 software (http://www.esri.com/arcgis), point density has been used to show the spatial distribution of COVID -19 patients in in all rural and urban districts of this province.

At first, the incidence of COVID-19 infection during the study period was calculated. Then, the incidence rate (IR) was mapped on urban and rural digital maps based on a scale of 1/100,000. All 
analyses were performed by rural and urban-level districts, as basic units of analysis. In addition, its spatial distribution in urban areas of the province was investigated using Moran's coefficient. According to Moran coefficient, there are three fundamental spatial point patterns: complete spatial randomness (CSR), regularity and clustering [17]. Furthermore, the spatial autocorrelation of the novel coronavirus in the different urban districts of the province was calculated by using the local indicators of spatial association (LISA) analysis. This index explains the spatial relationship pattern of a spatial parameter in the neighborhood. With the help of this statistic, points with low or high values that are distributed in clusters or values with high value differences (with a random pattern) can be displayed [18]. It is possible to display points in this statistic with four modes: High-High (HH), High-Low (HL), Low-High (LH), Low-Low (LL). The interpretation of these four categories is shown in Table 1. The local spatial autocorrelation determined from following formula:

$I_{i}=\frac{X_{i}-\bar{X}}{\mathrm{~S}_{i}^{2}} \sum_{j=1, j \neq i}^{n} W_{i, j}\left(X_{i}-\bar{X}\right)(1)$

$x_{i}=$ characters of parameter $\mathrm{i}$

$\bar{X}=$ the mean of parameters

$W i=$ the matrix of weights that in some cases is equivalent to a binary matrix with ones in position $\mathrm{i}, \mathrm{j}$

$S_{i}^{2}=\frac{\sum_{j=1, j \neq i}^{n}\left(X_{i}-\bar{X}\right)^{2}}{\mathrm{n}-1}(2)$

$Z_{i j}=\frac{I_{i}-\mathrm{E}\left[I_{i}\right]}{\sqrt{V\left[I_{i}\right]}}$

$\mathrm{E}\left[I_{i}\right]=-\frac{\sum_{j=1, j \neq i}^{n} W_{i j}}{\mathrm{n}-1}$

$V\left[I_{i}\right]=E\left[I_{i}^{2}\right]-E\left[I_{i}\right]^{2}$

Table 1 The interpretation the results of the local indicators of spatial association (LISA).

\begin{tabular}{lll}
\hline Categories & Autocorrelation & Interpretation \\
\hline HH & Positive & $\begin{array}{l}\text { Cluster }- \text { A high value area } \\
\text { surrounded by high value areas. }\end{array}$ \\
\hline
\end{tabular}




\begin{tabular}{lll}
\hline HL & Negative & $\begin{array}{l}\text { Complete spatial randomness - A } \\
\text { high value area surrounded by low } \\
\text { value areas }\end{array}$ \\
\hline LL & Positive & $\begin{array}{l}\text { Cluster }- \text { A low value area } \\
\text { surrounded by low value areas. }\end{array}$ \\
\hline LH & Negative & $\begin{array}{l}\text { Complete spatial randomness - a } \\
\text { low value area surrounded by high } \\
\text { values }\end{array}$ \\
\hline
\end{tabular}

\section{Results}

\section{The epidemiological features of patients}

A total of 4388 patients with COVID -19 have been diagnosed from February 19, 2020 to September 2020 in Qom province located in central Iran, most of whom were natives and residents of urban areas of the province. Also, most of cases was men over the age of 50 years (Table 2).

The prevalence of COVID -19 infection in Qom province was estimated to be 356.75 per 100,000 populations in a period of time from February 19, 2020 to September, 2020.

The monthly incidence of COVID -19 disease in Qom province showed that the frequency of cases was increasing from February to April, after the reduction of the disease in a period of two months,

Table 2 Some epidemiological characteristics of patients with COVID-19 in Qom Province, Central Iran from February 19, 2020 to September, 2020

\begin{tabular}{llccc}
\hline Cases & & $\mathbf{N}$ & $\mathbf{( \% )}$ \\
\hline \multirow{2}{*}{ Gender } & Male & 2340 & 53.32 \\
\cline { 2 - 4 } & Female & 2048 & 46.68 \\
\cline { 2 - 4 } & & \multicolumn{1}{c}{$<0$} & 2.04 \\
\cline { 2 - 4 } & & $10-30$ & 348 & 7.94 \\
\cline { 2 - 4 } Endemisity situation (Year) & $30-50$ & 1311 & 29.87 \\
\cline { 2 - 4 } & & 250 & 2639 & 60.15 \\
\cline { 2 - 4 } Residency status & Indigenous & 4340 & 98.9 \\
\cline { 2 - 4 } & None-indigenous & 48 & 1.1 \\
\hline & Urban & 4210 & 3.00 \\
\hline & Rural & 130 & 100 \\
\hline
\end{tabular}

More than a third of patients (31.33\%) had comorbidity. Chronic diseases such as diabetes, cardiovascular diseases, chronic lung diseases, chronic Kidney diseases, and Immune mediated diseases were the most prevalent comorbidities with $10.32,10.09,6.00,2.58$, and 1.56 respectively (Table 3).

Table 3 Frequency of risk factors in patients with COVID-19 and its deaths in Qom Province, Central Iran from February 19, 2020 to September, 2020 


\begin{tabular}{lcc}
\hline \multicolumn{1}{l}{ Risk factors } & Cases N $(\%)$ & Mortality rate \\
\hline Diabetes & $448(10.32)$ & $78(12.38)$ \\
\hline Cardiovascular diseases & $438(10.09)$ & $63(10.00)$ \\
\hline Chronic lung diseases & $260(6.00)$ & $57(9.05)$ \\
\hline Chronic kidney diseases & $112(2.58)$ & $17(2.70)$ \\
\hline Immune mediated diseases & $68(1.56)$ & $8(1.27)$ \\
\hline Liver diseases & $34(0.78)$ & $8(1.27)$ \\
\hline Sum of at risk cases & $1360(31.33)$ & $231(36.67)$ \\
\hline Non-at risk cases & $2980(68.67)$ & $399(63.33)$ \\
\hline Total & $4340(100)$ & $630(100)$ \\
\hline
\end{tabular}

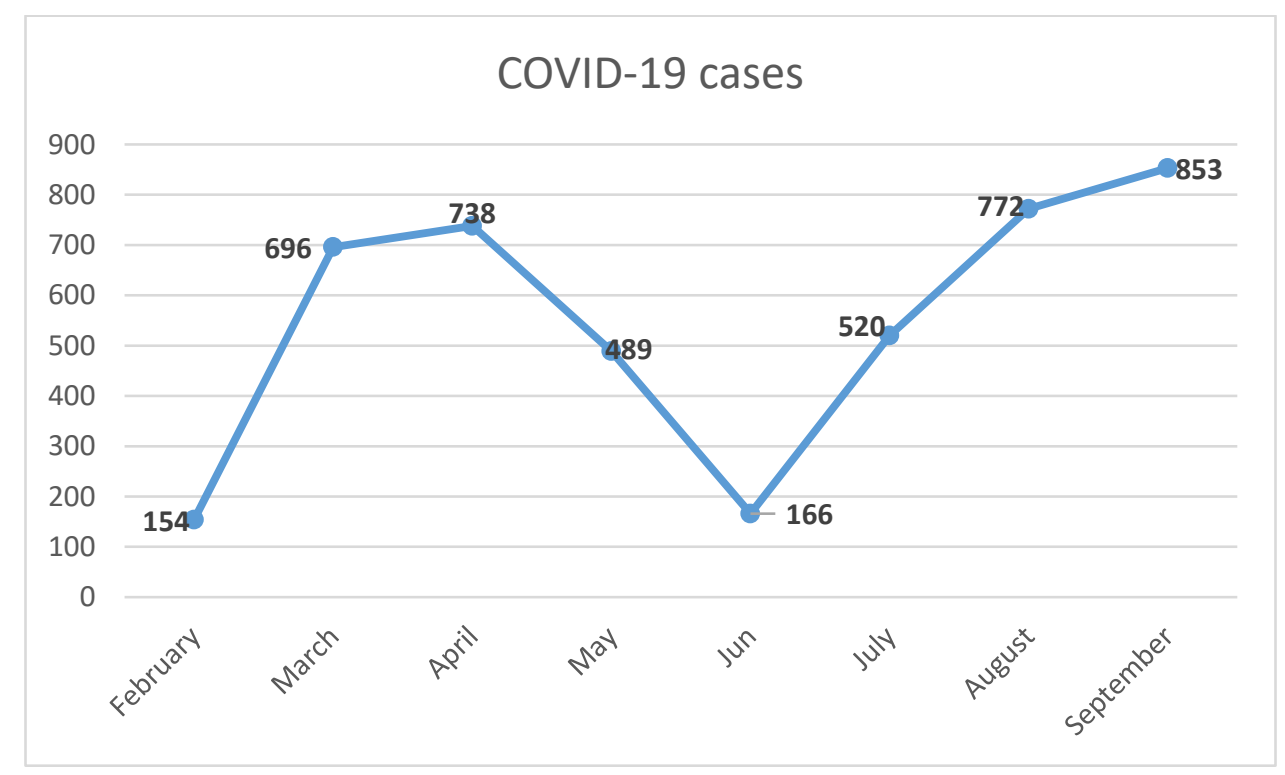

Fig. 2 The monthly incidence of COVID -19 disease in Qom Province, Central Iran from February 19, 2020 to September, 2020

\section{The spatial distribution of COVID-19 infection}

Spatial distribution maps of COVID -19 disease in Qom province show that most cases (97\%) of the disease occurred in the Markazi district and in the city of Qom and very few cases (3\%) have been reported in other rural districts. The cases of the disease (Figure 3). The prevalence of COVID -19 disease in urban districts is 350.49 per 100,000 people and in rural areas of Qom province is estimated at 4.51 per 100,000 populations. The prevalence of this disease in the urban districts showed that District 7 (Holy shrine), District 4 (Janbilabad-Salarieh), and District 6 (Imamzadeh Ebrahim Street) have the highest incidence of the disease in Qom (Table 4).

Table 4 Prevalence of COVID-19 infection in urban areas of Qom Province, Central Iran from February 19, 2020 to September, 2020 


\begin{tabular}{llll}
\hline Urban districts & Population & Cases & Incidence/100,000 \\
\hline $\mathbf{1}$ & 78401 & 243 & 309.94 \\
\hline $\mathbf{2}$ & 192060 & 671 & 349.37 \\
\hline $\mathbf{3}$ & 189708 & 642 & 338.41 \\
\hline $\mathbf{5}$ & 171363 & 808 & 471.51 \\
\hline $\mathbf{6}$ & 192755 & 642 & 333.06 \\
\hline $\mathbf{7}$ & 213356 & 930 & 435.89 \\
\hline $\mathbf{8}$ & 41625 & 227 & 545.34 \\
\hline
\end{tabular}



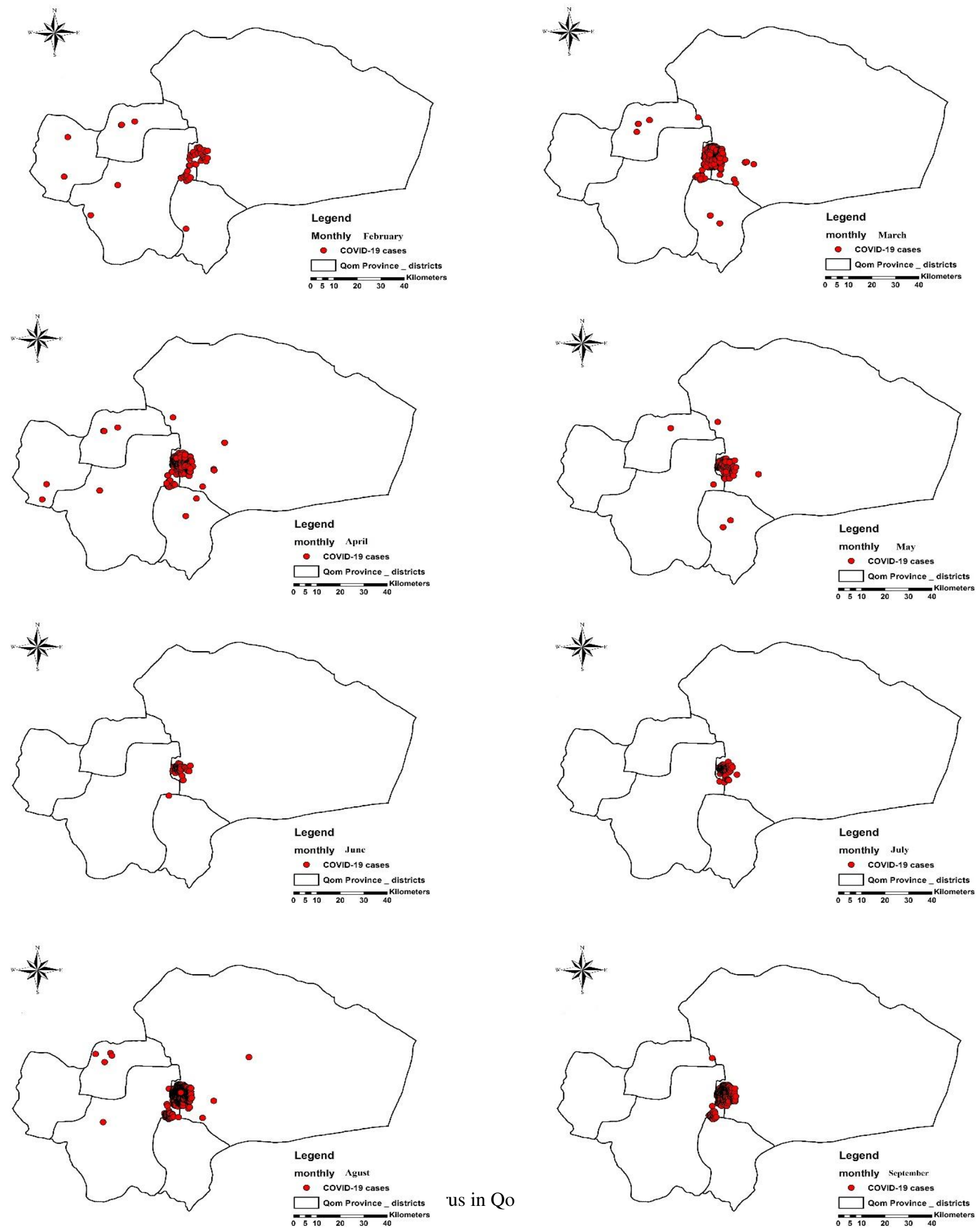


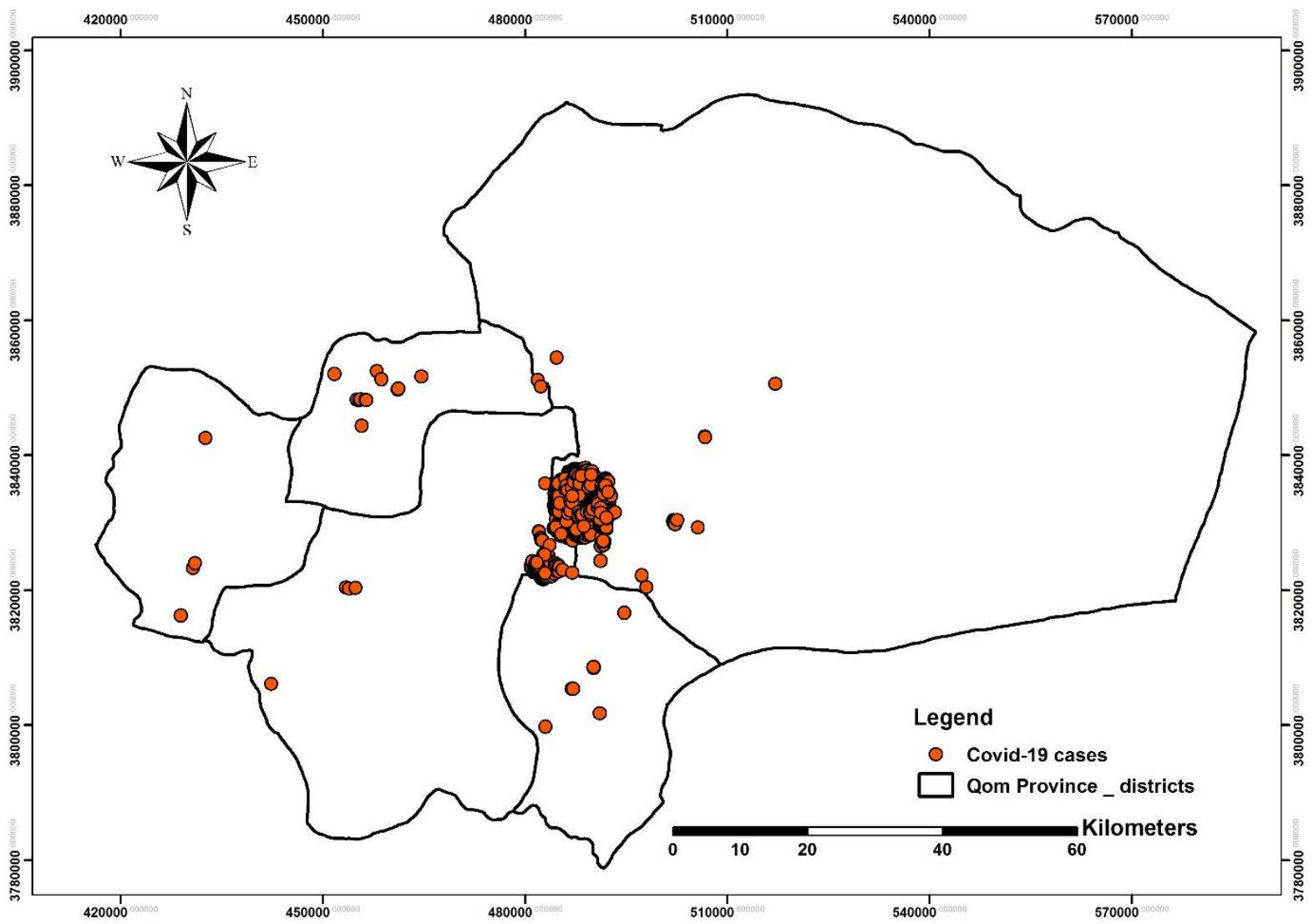

Fig. 4 Spatial distribution maps of novel corona virus in rural and urban areas of Qom Province, Central Iran from February 19, 2020 to September, 2020

\section{The point pattern analysis of COVID-19 in Qom province}

With the spread of the novel coronavirus in Qom province since February 19, 2020, in order to determination of point pattern analysis of COVID -19 in Qom province, Moran's Index was calculated (Moran's Index: 0.106709, Z-score: 1.730283 and p-value: 0.083580 with 90\% confidence interval). Based on which the pattern of spatial distribution of the prevalence of COVID -19 disease in Qom was clustered (Fig 5), which indicates the high prevalence of the disease in some areas of Qom, including urban districts 7, 4 and 6 respectively (Table 4). 


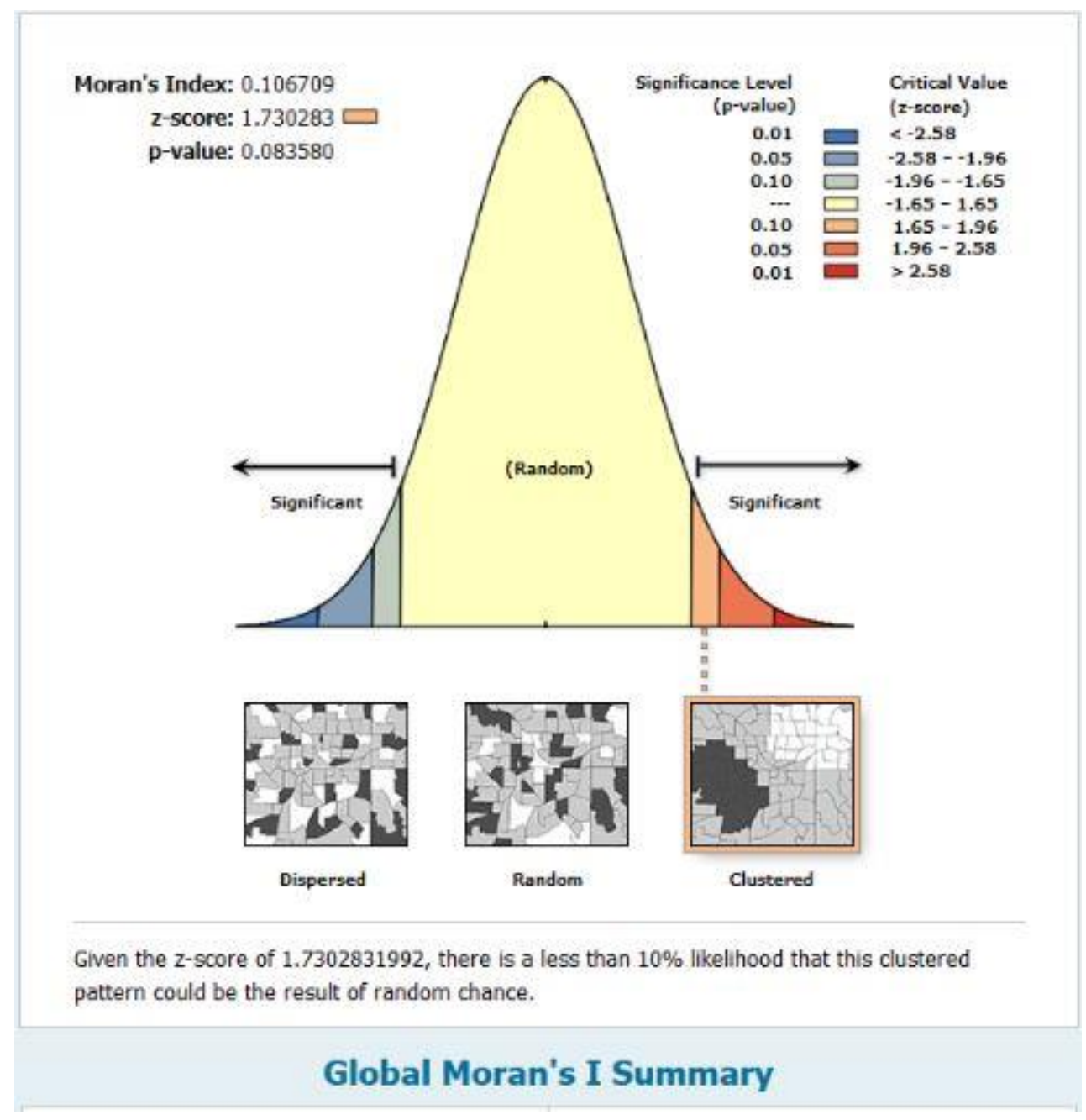

Fig. 5 The point pattern analysis of COVID-19 in Qom province, from February 19, 2020 to September, 2020

The spatial autocorrelation of the novel coronavirus using the local indicators of spatial association (LISA)

Based on analysis, the incidence of COVID -19 infection cases in District 3 (Imam Khomeini St.), and District 6 (Imamzadeh Ebrahim St.), as two districts of urban districts of Qom Province were set in HH category of LISA as two foci of COVID -19 in Qom province (Fig 6).

This means that the incidence of the disease in these two districts is higher (values above average) and those two districts also surrounded by high value areas (areas with a high incidence of patients with COVID -19). Also, autocorrelation in these two urban districts is positive and includes more than one third of the population of Qom (33.55\%).

In addition, based on LISA, District 1 (Bajak) of urban districts was set in LH category. It means this district is located in a low value area surrounded by high values (Fig 6). 


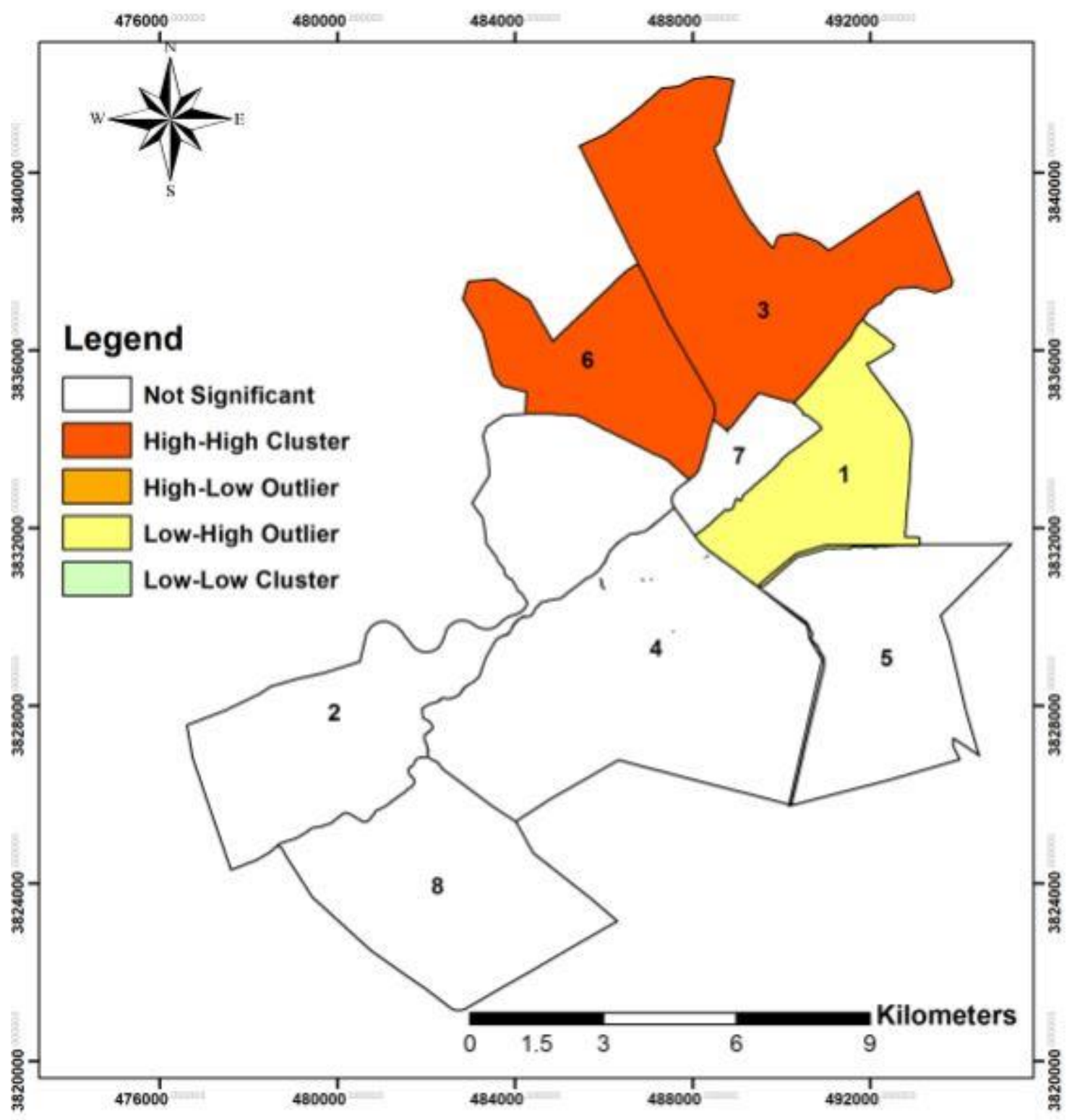

Fig. 6 The spatial autocorrelation of the novel coronavirus using the local indicators of spatial association (LISA) in urban districts of Qom City, from February 19, 2020 to September, 2020

\section{Discussion and Conclusion}

The coronavirus pandemic is currently causing the disruption daily life of human around the world and it is necessary to address this health issue and study it in terms of geographical features [19]. Based on the findings of present study, the prevalence of COVID -19 infection in Qom province was estimated to be 356.75 per 100,000 populations in a period of time from February 19, 2020 to 
September, 2020. Following the ongoing spread of the COVID -19, in the world, the outbreak of this disease in Iran and from the city of Qom on February 20, 2020 was confirmed [16]. The monthly incidence of COVID-19 disease in Qom province showed that the frequency of cases was increasing from February to April, after the reduction of the disease in a period of two months, the cases have increased again in the following months. It seems that the observance of health protocols such as social distancing, regular hand washing, the use of masks and gloves, disinfection of fruits and vegetables, disinfection of surfaces, and personal hygiene by the people has reduced the incidence of disease in May and June. The results of this study showed that men over the age of 50 accounted for more than $60 \%$ of all coronavirus infected people. Furthermore, according to the results, more than a third of patients had comorbidity. Chronic diseases such as diabetes, cardiovascular diseases, chronic lung diseases, chronic Kidney diseases, and Immune mediated diseases were the most prevalent comorbidities. This point indicates that middle-aged and elderly people in Qom have been the most infected with the novel corona virus, which in the event of an increase in human deaths in this age group, the household economy and consequently the economic cycle of the province will face problems. Studies on the epidemiological characteristics of coronavirus in Iran so far also show that the proportion of men with coronavirus is higher than women and most cases are in the age range of 50-60 years [20,21].

In another study conducted at Baqiyatallah Hospital in Tehran, more than $10 \%$ of patients with COVID -19 infection had comorbidity [21]. This indicates that people with chronic diseases are at risk for COVID-19 disease and need more care. Recent research has shown that the high incidence of COVID-19 in the elderly is due to cognitive impairment, immunodeficiency, underlying diseases, malnutrition, multiple drug use, and social problems. For this reason, in developing countries, the number of elderly people suffering from death from COVID -19 is higher than in other age groups [22]. Based on spatial distribution maps of COVID -19 disease in Qom province most cases of the disease occurred in the city of Qom in comparison of rural districts. The results of this study indicates that the pattern of spatial distribution of the prevalence of COVID-19 disease in Qom was clustered. Furthermore, incidence of COVID -19 infection cases in District 3 (Imam Khomeini St.), and District 6 (Imamzadeh Ebrahim St.), as two urban districts of Qom Province were set in HH category of LISA as two foci of COVID -19 in Qom province. This finding means that the incidence of the disease in these two districts is higher (values above average) and those 
two districts also surrounded by high value areas (areas with a high incidence of patients with COVID -19). Also, autocorrelation in these two urban districts is positive and includes more than one third of the population of Qom. Also, based on LISA, District 1 (Bajak) of urban districts was set in LH category. It means this district is located in a low value area surrounded by high values. Because of its spatial interaction with areas at high risk of coronavirus transmission, precautionary preventive measures to control of coronavirus infection in this area should be intensified. It seems that one of the most important factors in the spatial spread of coronavirus in Qom province is the centralization of population distribution in the Qom City and around the holy shrine, which in the coronavirus pandemic situation has caused the spread of this communicable disease. In a study conducted in Hubei Province, China, the results of the spatial pattern of the Moran coefficient showed that spatial clusters with an increasing trend and sudden change, due to the high concentration of population has caused the outbreak of Corona virus in this province [23]. In the present study, the concentration of population in Qom has led to the formation of a cluster pattern in the distribution of this disease.

According to the results, one of the most important geographical factors affecting the incidence of coronavirus is based on spatial distribution model, distance and spatial proximity. So, health policy makers and planners in the province, should impose more bans and restrictions on the observance of health protocols to control of the coronavirus. In addition, it is recommended to implement preventive matures such as social distancing in high-traffic areas especially District 3 (Imam Khomeini St.), and District 6 (Imamzadeh Ebrahim St.), as two foci of COVID -19 of Qom City more than before to cut the chain of disease transmission.

\section{Abbreviations}

LISA: Local indicators of spatial association; SARS-CoV-2: Severe acute respiratory syndrome coronavirus 2; WHO: World Health Organization

\section{Supplementary Information}

The supplementary material available at Department of Public Health, Faculty of Health, Qom University of Medical Sciences, Qom, Iran

Acknowledgements

Ethical issues (Including plagiarism, informed consent, misconduct, data fabrication and/or falsification, double publication and/or submission, redundancy, etc.) have been completely observed by the authors. Funding for this research was provided by the Research and Technology Center of Qom University of Medical Sciences (IR.MUQ.REC.1399.036). The authors are grateful 
to the research deputy of Qom University of Medical Science and Department of Disease Control and Prevention, Qom Provincial Health Center, Qom University of Medical Sciences, Qom, Iran. Authors' contributions

AS and NJ co-designed the study and wrote the paper. AS, NJ, MKJ Analyzed and interpreted the data. AS, $\mathrm{AK}, \mathrm{BF}, \mathrm{NJ}$ and MKJ Contributed reagents, materials, analysis tools or data. SA and MS collected the primary data.

Funding

Funding for this research was provided by the Research and Technology Center of Qom University of Medical Sciences (IR.MUQ.REC.1399.036).

Availability of data and materials

The datasets used and/or analysed during the current study are available from the corresponding author on reasonable request.

\section{Declarations}

Ethics approval and consent to participate

This study was approved by Research and Technology Center of Qom University of Medical Sciences IR.MUQ.REC.1399.036

Consent for publication Not applicable.

Competing interests

The authors declare no competing interests.

\section{References}

1. Chen N, Zhou M, Dong X, Qu J, Gong F, Han Y, et al. Epidemiological and clinical characteristics of 99 cases of 2019 novel coronavirus pneumonia in Wuhan, China: a descriptive study. Lancet 2020; 395: 507-513.

2. WHO. Naming the coronavirus disease (COVID-19) and the virus that causes it. Available at: https://www.who.int/emergencies/diseases/novel-coronavirus-2019/technical-guidance/naming-the-

coronavirus-disease-(covid-2019)-and-the-virus-that-causes-it

3. United Nations Comprehensive Response to C OV I D -19: Saving Lives, Protecting Societies, Recovering Better. Available at: https://www.un.org/sites/un2.un.org/files/un_comprehensive_response_to_covid-19_june_2020.pdf 4. Jayaweera, M, Perera H, Gunawardana B, Manatunge J. Transmission of COVID-19 virus by droplets and aerosols: Acritical review on the unresolved dichotomy. Environ Res 2020; 188: 109819.

5. Saghafipour A. Indirect and Potential Impacts of the COVID-19 Pandemic on the Public Health. J Res Health Sci 2020 ;

20(3); e00492.

6. Nii-Trebi NI. Emerging and Neglected Infectious Diseases: Insights, Advances, and Challenges. Biomed Res Int 2017; 2017:5245021. doi: 10.1155/2017/5245021.

7. Elliott $\mathrm{P}$, Wartenberg D. Spatial epidemiology: current approaches and future challenges. Environ Health Perspect 2004;112(9):998-1006. doi: 10.1289/ehp.6735

8. Aghajani J, Farnia P, Velayati AA. Impact of geographical information system on public health sciences. Biomed Biotechnol Res J 2017; 1:94-100. doi: 10.4103/bbrj.bbrj_34_17

9. Salimi M, Jesri N, Javanbakht M, Farahani LZ, Shirzadi MR, Saghafipour A. Spatio-temporal distribution analysis of zoonotic cutaneous leishmaniasis in Qom Province, Iran. J Parasit Dis 2018;42(4):570-576. doi: 10.1007/s12639-018-1036-5.

10. Mohammadbeigi A, Saghafipour A, Jesri N, Tarkhan FZ, Jooshin MK. Spatial distribution of vaccinepreventable diseases in central Iran in 2015-2018: A GIS-based study. Heliyon 2020 30;6(9): e05102. 
11. Akbarzadeh K, Saghafipour A, Jesri N, Karami-Jooshin M, Arzamani K, Hazratian T, Kordshouli RS, Afshar AA. Spatial Distribution of Necrophagous Flies of Infraorder Muscomorpha in Iran Using Geographical Information System. J Med Entomol 2018;55(5):1071-1085.

12. Fradelos EC, Papathanasiou IV, Mitsi D, Tsaras K, Kleisiaris CF, Kourkouta L. Health Based Geographic Information Systems (GIS) and their Applications. Acta Inform Med 2014;22(6):402-405.

13. Chowell G, Rothenberg, R. Spatial infectious disease epidemiology: on the cusp. BMC Med 2018; 16: 192.

14. Anselin L. Exploratory spatial data analysis in a geocomputational environment. 1998; Pp. 77-94 in Geocomputation: A Primer, edited by P.A. Longley, S.M. Brooks, R. McDonnell, and W. Macmillian. New York: Wiley and Sons.

15. Farzinnia B, Saghafipour A, Abai M. Malaria Situation and Anopheline Mosquitoes in Qom Province, Central Iran. Iran J Arthropod Borne Dis 2010;4(2):61-67.

16. Ghadir MR, Ebrazeh A, Khodadadi J, Zamanlu M, Shams S, Nasiri M, et al. The COVID-19 Outbreak in Iran; The First Patient with a Definite Diagnosis. Arch Iran Med 2020; 23:503-504.

17. Cressie NAC. Statistics for spatial data. Wiley series in probability and mathematical statistics: Applied probability and statistics. J. Wiley, 1993.

18. Yamada I, Thill JC. Local indicators of network-constrained clusters in spatial point patterns. Geogr Anal 2007; 39(3): 268-292.

19. Haleem A, Javaid M, Vaishya R. Effects of COVID-19 pandemic in daily life. Curr Med Res Pract 2020;10: 7879.

20. Nikpouraghdam M, Farahani AJ, Alishiri G, Heydari S, Ebrahimnia M, Samadinia H, et al. Epidemiological characteristics of coronavirus disease 2019 (COVID-19) patients in IRAN: A single center study. J Clin Virol 2020;127: 104378.

21. Bazargan M, Amirfakhriyan M. Geographical Analysis of COVID-19 Epidemiology in Iran with Exploratory Spatial Data Analysis Approach (ESDA). J Mil Med 2020; 22 (6) :542-552.

22. Benksim A, Addi RA, Cherkaoui M. Vulnerability and Fragility Expose Older Adults to the Potential Dangers of COVID-19 Pandemic. Iran J Public Health 2020; 49(1): 122-24.

23. Wentao Y, Min D, Chaokui L, Jincai H. Spatio-Temporal Patterns of the 2019-nCoV Epidemic at the County Level in Hubei Province, China. Int J Environ Res Public Health 2020;17(7):2563. 